\title{
Effect of Heat Treatment on Fe-B-Si-Nb Alloy Powder Prepared by Mechanical Alloying
}

\author{
Rodrigo Estevam Coelho ${ }^{\mathrm{a} *}$, Rodinei Medeiros Gomes ${ }^{\mathrm{b} *}$, Severino Jackson Guedes de Lima ${ }^{\mathrm{b} *}$ \\ ${ }^{a}$ Centro Federal de Educação Tecnológica da Bahia, \\ Departamento de Tecnologia Mecânica e Materiais, Salvador - BA, Brazil \\ ${ }^{\mathrm{b}}$ Centro de Tecnologia, Departamento de Tecnologia Mecânica, \\ Universidade Federal da Paraíba, Campus I, João Pessoa - PB, Brazil
}

Received: November 23, 2003; Revised: March 7, 2005

\begin{abstract}
The effect of heat treatment on crystallization behavior of $\mathrm{Fe}_{73.5} \mathrm{~B}_{15} \mathrm{Si}_{10} \mathrm{Nb}_{1.5}$ alloy powder prepared by mechanical alloying was studied. The powder samples were prepared by mechanical alloying (MA) and for different milling times (1, 5, 25, 70 and 100 hours). Crystalline powders of iron, boron, silicon and niobium were sealed with tungsten carbide balls in a cylindrical vial under nitrogen atmosphere. The ball-to-powder weight ratio was 20 to 1 . A Fritsch Pulverizette 5 planetary ball mill was used for MA the powders at room temperature and at $250 \mathrm{rpm}$. To study the microstructural evolution, a small amount of powder was collected after different milling times and examined by X-ray diffraction, using $\mathrm{CuK} \alpha$ radiation $(\lambda=0.15418 \mathrm{~nm})$. The crystallization behavior was studied by differential thermal analysis, from 25 up to $1000{ }^{\circ} \mathrm{C}$ at a heating rate of $25^{\circ} \mathrm{C} \mathrm{min}{ }^{-1}$.
\end{abstract}

Keywords: mechanical alloying, FeBSiNb powder, crystallization

\section{Introduction}

In the last two decades there has been growing interest in amorphous and nanocrystalline alloys based on $\mathrm{Fe}-\mathrm{Si}-\mathrm{B}$. Amorphous and nanocrystalline alloys obtained by the melt spinning technique belong to a group of soft magnetic materials, with magnetic properties significantly better than conventional silicon steels ${ }^{1,2}$. Moreover, these materials reveal relatively high resistivity, which drastically reduces eddy current losses (lower hysteresis).

Magnetic properties of amorphous alloys with the right chemical composition can be considerably improved with controlled heat treatment. This is due to the formation of a nanocrystalline phase, and leads to random distribution of material and magnetic anisotropy. The kinetics of formation of the nanocrystalline phase depends strongly on alloy chemistry. As has been observed, alloying additions to $\mathrm{Fe}-\mathrm{Si}-\mathrm{B}$ based alloys can change the mechanism of nucleation or growth rate of the nanocrystalline phase ${ }^{1-3}$. Consequently, the magnetic properties of the material, as well as the electrical properties, are strongly influenced by the annealing conditions (temperature/time) and lead to the formation of a nanophase. Some studies have found that with the addition of copper or niobium to an Fe-Si-B based alloy, a new nanostructured soft magnetic material forms after crystallization at about $550{ }^{\circ} \mathrm{C}^{4,5}$. Appropriate alloy chemistry and annealing conditions enable the production of material with desirable physical properties for specific applications. The effect of temperature on crystallization kinetics of amorphous alloys has been investigated in several systems. Temperature affected significantly the transformation behavior of amorphous alloys and often led to the formation of dense, metastable crystalline phases that were not encountered during transformation at atmospheric pressure ${ }^{6,7}$. The effect of temperature on crystallization kinetics and stage of nucleation of crystals is associated with atomic diffusion processes. The initial transformation in the amorphous phase depends on temperature, chemical composition and the process ${ }^{8,9}$.

In this study an amorphous $\mathrm{Fe}_{73.5} \mathrm{~B}_{15} \mathrm{Si}_{10} \mathrm{Nb}_{1.5}$ alloy was prepared by mechanical alloying a mixture of elemental powders and then heat treated for crystallization. The results of X-ray diffraction analysis and differential thermal analysis carried out on this alloy are presented.

\section{Experimental Procedure}

Elemental powders of $\mathrm{Fe}(100 \mu \mathrm{m}, 99.7 \%$ purity $), \mathrm{B}, \mathrm{Si}$ and $\mathrm{Nb}$ (99.9\% purity) were mixed in proportions corresponding to the nominal composition $\mathrm{Fe}_{73.5} \mathrm{~B}_{15} \mathrm{Si}_{10} \mathrm{Nb}_{1.5}$ (at \%) and mechanically alloyed in a high-energy planetary ball mill (Fritsch Pulverisette 5). The powder mixture and tungsten carbide balls were sealed in a cylindrical tungsten carbide vial under argon atmosphere. The ball-to-powder weight ratio was 20 to 1 , and milling was carried out at room temperature and at $250 \mathrm{rpm}$ for 1, 5, 25, 70 and 100 hours. After milling, the powders were removed in air atmosphere.

The milled samples were analyzed by X-ray diffraction and differential thermal analysis (DTA). X-ray diffraction measurements were carried out in a Siemens D5000 with $\operatorname{CuK} \alpha(\lambda=0.15418 \mathrm{~nm})$ radiation. The DTA experiments were carried out in a Shimadzu DTA, in a dynamic nitrogen atmosphere, with heating from 25 to $1000{ }^{\circ} \mathrm{C}$ at $25^{\circ} \mathrm{C} / \mathrm{min}$.

Samples milled for 100 hours were heated from 25 to $1000^{\circ} \mathrm{C}$ at $25^{\circ} \mathrm{C} / \mathrm{min}$ in a tube furnace with a flow of nitrogen.

\section{Results and Discussion}

Figure 1 shows selected X-ray diffraction (XRD) patterns of $\mathrm{Fe}_{73.5} \mathrm{~B}_{15} \mathrm{Si}_{10} \mathrm{Nb}_{1.5}$ (at\%) powders as a function of milling time. The pattern of the powder milled for 1 hour was regarded as a reference and in it the peaks of the starting components $\mathrm{Fe}, \mathrm{B}$ and $\mathrm{Si}$ appear. The pattern of the powder milled for 5 hours did not reveal any significant change. The $\mathrm{Nb}$ peaks were not observed as the amount of $\mathrm{Nb}$ in the overall composition was very small. After MA for 25, 70 and 100 hours, the intensity of the iron peaks decreased and widened significantly, while those of boron and silicon disappeared. 
Generally, with increasing milling time the intensity of the peaks decrease. This is due to several factors, such as increase in the amount of strain introduced in the powder particles and increase in the number of defects and vacancies. On the other hand, this alloy $\left(\mathrm{Fe}_{73.5} \mathrm{~B}_{15} \mathrm{Si}_{10} \mathrm{Nb}_{1.5}\right)$, tends to lose crystallinity during MA, as found in this study. Amorphization during MA is not a purely mechanical process. It is a solid-state reaction, similar to that observed in materials obtained by rapid solidification. The continuous decrease in grain size, consequent increase in grain boundary area and lattice expansion, also contributes to increase in free energy of the system. The amorphization occurred when a large quantity of impurity atoms (other elements) penetrated the interstitial sites and distorted locally the lattice. In this case, an amorphous phase is formed due to high milling intensities. However, in XRD patterns of the powder milled for 25, 70 and 100 hours, the presence of crystalline phases can be observed $\left(\mathrm{Fe}_{2} \mathrm{~B}\right.$ and $\left.\mathrm{Fe}_{3} \mathrm{~B}\right)$ along with $\mathrm{Fe}_{3} \mathrm{O}_{4}$ contamination, due to the long milling time. Partial amorphization is considered to have taken place in the material processed in this investigation. This is of relevance in experiments that have been planned and in which mechanical alloying process parameters such as recipient material, milling balls, atmosphere, stoppages, velocity, and use of lubricants will be varied.

Figure 2 shows the DTA curves after one and two heating runs of $\mathrm{Fe}_{73.5} \mathrm{~B}_{15} \mathrm{Si}_{10} \mathrm{Nb}_{1.5}$ (at\%) powder samples processed for 100 hours. In the curve after the first heating run, one peak appeared and this corresponds to an exothermic reaction, attributable to crystallization of the amorphous phase. The initial, maximum and end of crystallization temperatures are 591, 626 and $659{ }^{\circ} \mathrm{C}$, respectively. In the curve after the second heating run, no transformation was observed, and this indicated that the crystalline phases formed during heating were thermally stable.

The formation of crystal phases in $\mathrm{Fe}_{73.5} \mathrm{~B}_{15} \mathrm{Si}_{10} \mathrm{Nb}_{1.5}$ (at\%), as determined by XRD are presented in Figure 3. The XRD pattern of the powder milled for 100 hours and annealed from 25 to $1000{ }^{\circ} \mathrm{C}$ is shown in Figure 3. In the crystallized sample, XRD peaks of $\mathrm{Fe}$, $\mathrm{Fe}_{2} \mathrm{~B}$ and $\mathrm{FeSi}$ solid solution were observed. The $\mathrm{Fe}_{3} \mathrm{~B}$ peak was not observed as this phase is not stable. On the other hand, $\mathrm{Fe}_{2} \mathrm{~B}$ and FeSi solid solution are stable phases. Previous studies indicated that the FeSi solid solution forms easily. Large quantities of silicon (e.g. $\mathrm{Fe} 50 \% \mathrm{Si}$ ) appeared after shorter milling times and this phase is a paramagnetic compound ${ }^{10}$. Considering these aspects, in this study the $\mathrm{Fe}_{2} \mathrm{~B}$ phase and $\mathrm{FeSi}$ solid solution are distributed in the Fe matrix.

\section{Conclusions}

A Fe-B-Si-Nb powder mixture corresponding to $\mathrm{Fe}_{73.5} \mathrm{~B}_{15} \mathrm{Si}_{10} \mathrm{Nb}_{1.5}$ (at $\%$ ) composition was prepared by mechanical alloying. The amorphous and crystalline phases that formed were studied. The structure was characterized by X-ray diffraction analysis and differential thermal analysis. The main conclusions are summarized as follow:

a) X-ray diffraction analysis showed the evolution of the amorphous phase in powders milled for several times;

b) The amorphous phase formed in powders milled for long periods, but in powders milled for up to 25 hours, the formation of crystalline phases $\left(\mathrm{Fe}_{2} \mathrm{~B}\right.$ and $\left.\mathrm{Fe}_{3} \mathrm{~B}\right)$ was also observed;

c) $\mathrm{Fe}_{3} \mathrm{O}_{4}$ contamination was observed in powders milled for long periods and the source, the milling vial;

d) In the first DTA cycle one peak was observed which corresponded to an exothermic transformation and attributed to crystallization of the amorphous phase; and

e) In the second DTA cycle no transformation was observed and the pattern showed no $\mathrm{Fe}_{3} \mathrm{~B}$ phase, since this phase is not stable. The $\mathrm{Fe}_{2} \mathrm{~B}$ and $\mathrm{FeSi}$ solid solution are stable phases, and these were present after formation.

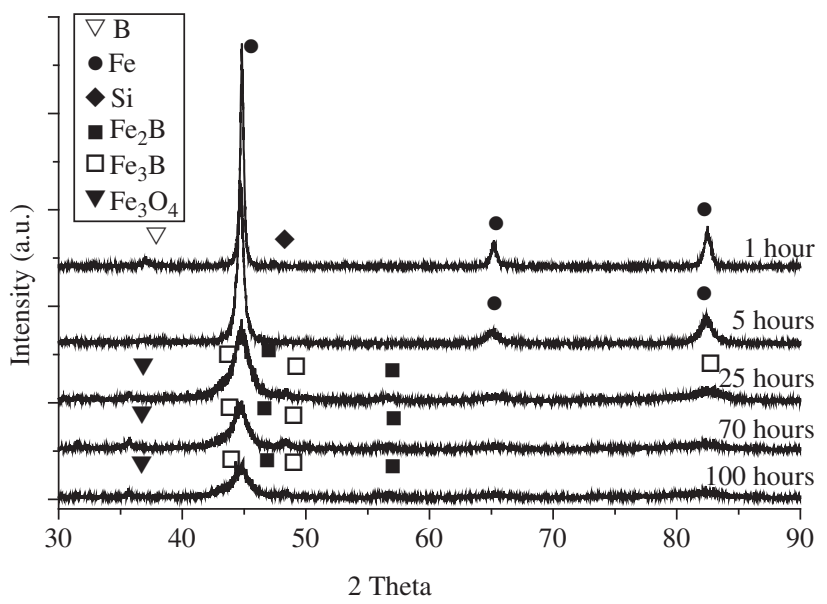

Figure 1. XRD patterns of powders of $\mathrm{Fe}, \mathrm{B}, \mathrm{Si}$ and $\mathrm{Nb}$ mixed in proportions corresponding to $\mathrm{Fe}_{73.5} \mathrm{~B}_{15} \mathrm{Si}_{10} \mathrm{Nb}_{1.5}$ (at\%) and milled for 1, 5, 25, 70 and 100 hours.

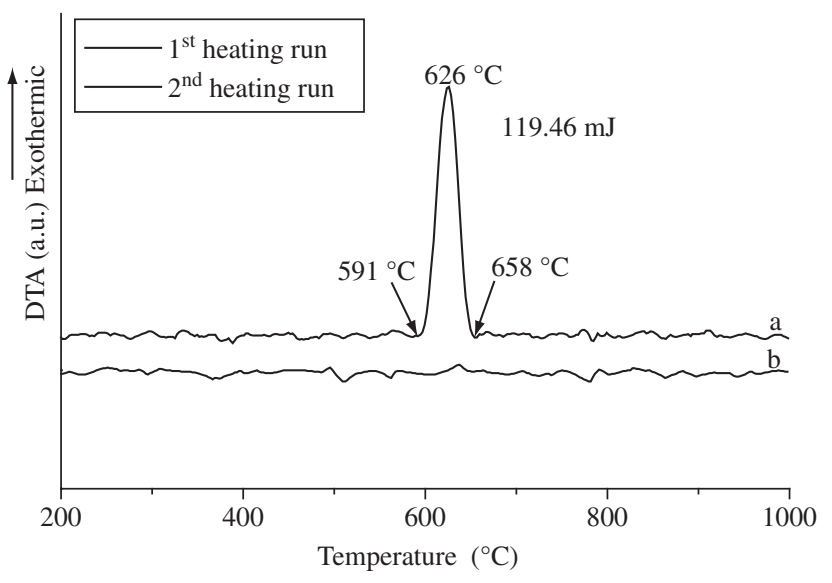

Figure 2. DTA curves of the $\mathrm{Fe}_{73.5} \mathrm{~B}_{15} \mathrm{Si}_{10} \mathrm{Nb}_{1 . .5}$ (at\%) powders milled for 100 hours.



Figure 3. XRD patterns of Fe-B-Si-Nb mixture (with $\mathrm{Fe}_{73.5} \mathrm{~B}_{15} \mathrm{Si}_{10} \mathrm{Nb}_{1.5}$ (at \%) composition) milled for 100 hours and heat treated up to $1000^{\circ} \mathrm{C}$. 


\section{Acknowledgments}

The authors wish to thank CNPq for the financial support of this project. They also thank the technicians Mr. Itânio Veloso and Miss Maria Lucia Carvalho for their helpful suggestions.

\section{References}

1. McHenry ME, Willard MA, Laughlin DE. Amorphous and nanocrystalline materials for applications as soft magnets. Prog. Mater. Sci. 1999; 44(4):291-433.

2. Varga LK, Mazaleyrat F, Kováè J, Kákay A. Soft magnetic properties of nanocrystalline $\mathrm{Fe}_{100-\mathrm{x}} \mathrm{Si}_{\mathrm{x}}(15<\mathrm{x}<34)$ alloys; J. Magn Magn Mater; 2000; 215-216:121-123

3. Inoue A, Makino A, Mizushima T, Ferromagnetic Bulk Glassy Alloys. J. Magn Magn Mater. 2000; 215-216:246.

4. Yoshizawa Y, Oguma Y, Yamauchi K, New Fe-based soft magnetic alloys composed of ultrafine grain structure. J. Appl. Phys. 1988; 64(10):60446046.
5. Feng W, He KY, Gheng LZ, Xu H, Dong X Q, Zhang YM. Change of structure of the $\mathrm{Fe}_{735} \mathrm{Cu}_{1} \mathrm{Nb}_{3} \mathrm{Si}_{135} \mathrm{~B}_{9}$ alloy by mechanical alloying. Nanostr. Mater. 1997; 8(3): 367-371.

6. Gu XJ, Ye F, Zhou F, Lu K. Pressure effect on crystallization of mechanically alloyed amorphous $\mathrm{Al}_{85} \mathrm{Fe}_{15}$ alloy. Mater. Sci. Eng. 2000; A278: 61-65.

7. Wang WK, Iwasaki H, Suryanarayana C, Masumoto T. Crystallization characteristics of an amorphous $\mathrm{Ti}_{80} \mathrm{Si}_{20}$ alloy at high pressures. J. Mater. Sci. 1983; 18:3765-3772.

8. He Y, Shiflet GJ, Poon SJ. Ball milling-induced nanocrystal formation in aluminum-based metallic glasses. Acta. Metall. Mater. 1995; 43(1):8391.

9. Kim YH, Inoue A, Masumoto T. Structural relaxation of aluminum-lanthanide metal-transition metal amorphous alloys upon low temperature annealing J. Non-Crystalline Sol. 1991; 127(3):233-241.

10. Lima SJG, Pontes LRA, Viana SG, Silva JHE, Lima ICE. Empirical modeling for mechanical alloying applied to FeSi alloy. In: Nineteenth IASTED International Conference - MIC 2000, 2000, Innsbruck - Austria, Anaheim, Calgary, Zurich: IASTED/ACTA Press, 2000. p. 619-623. 